\title{
Dynamic Capabilities: Do They Really Matter in Strategy Implementation? Evidence from Small and Medium Manufacturing Firms in Kenya
}

\author{
Peter Kihara ${ }^{1, *}$ \\ ${ }^{1}$ School of Business and Economics, Kenya Methodist University, P.O. Box 45240-00100, Nairobi, Kenya \\ *Correspondence: School of Business and Economics, Kenya Methodist University, P.O. Box 45240-00100, Nairobi,
} Kenya. E-mail: Peter.Kihara@kemu.ac.ke

Received: July 6, 2018 Accepted: July 20, 2018 Online Published: July 25, 2018

doi:10.5430/sass.v5n2p44 URL: https://doi.org/10.5430/sass.v5n2p44

\begin{abstract}
Scholars believe that implementation of a strong strategy is a panacea to superior business firm's performance. This study tested the influence of five dynamic capability drivers on the performance of manufacturing firms. The Dynamic Capability's View of the firm provided a useful framework where these drivers were analyzed using a sample of 115 firms. Results from four drivers confirm that dynamic capabilities positively influences firm's performance. These drivers are technology, human resource, leadership style and structure. Strategic direction only influences other drivers but not performance. When all the drivers are combined, only structure and technology matters in influencing firm's performance. This study recommends use of strong dynamic capabilities to drive the strategy implementation efforts to success.
\end{abstract}

Keywords: dynamic capabilities, manufacturing firm, strategy implementation, performance

JEL CLASSIFICATION: M10; L10; L60; C12

\section{Introduction}

Small and medium manufacturing firms need to continuously implement new and superior strategies in order to survive the dynamic and competitive environments which they operate in. The new strategies enable these firms to develop new and better products or to modify the existing ones in order to improve their visibility and competitiveness in the market. However, the art of implementing new strategies is not an easy process due to many challenges encountered in between and the time consumed. Strategy implementation is the second stage after strategy formulation and often regarded by many scholars as the most important yet very difficult compared to other stages in strategic management process (Sial, Usman, Zufiqar, Satti \& Khurheed, 2013).

The growth and survival of firms in the manufacturing sector depends on how fast they develop new and better strategies and how well these strategies put to work. Poor implementation of strategies may be very costly venture in terms of lost sales and competitiveness. Past studies have documented the existence of a positive relationship between strategy implementation and firm's performance (Hrebiniak \& Joyce, 1984; Li, Gouhui \& Eppler, 2010). Therefore, it follows that a firm that implements a strong and unique strategy is able to achieve superior performance among the rival firms especially in highly competitive industries where unique strategies are difficult to achieve (Sage, 2015, Noble, 1999). Several researchers have underscored the importance of strategy implementation in the following observations, that strategy implementation is a critical process that guarantees proper functioning and survival of an organization during turbulent times (Sial et al., 2013), all business organizations require smart strategies to succeed in a competitive environment (Noble, 1999), superior and adaptive strategies enables an organization perform better and attain a competitive edge (Awino, 2013; Okwachi, Gakure \& Ragui, 2013), both practical experience and research indicate that strategy implementation impacts strongly on firms' performance.

Strategy implementation is often viewed as a dynamic activity within the strategic management process that define how organizations develops, utilizes and amalgamate organizational structures, control systems and manage culture 
when implementing strategies that lead to competitive advantage and improved performance (Jooste \& Fourie, 2009; Sorooshian, Norzima, Yusuf \& Rosnah, 2010). The Dynamic Capability View of the firm attributes superior performance of a firm to the existence of unique capabilities that are difficult to develop, copy,

acquire or to imitate. Examples of these capabilities include dynamic processes, unique structures, strong leadership styles and superior technology that is matched to the market needs. When strategy implementation process is viewed as a dynamic capability in a business firm, then it follows that the process should always be driven to success by procession and usage of dynamic capabilities as stipulated by the Dynamic Capability View of the firm.

The main focus of this study is to determine whether the key dynamic capabilities drivers identified in this study influence the performance of manufacturing small and medium firms in Kenya. The firms' structure, strategic intention, use of technology and leadership style are the main capabilities investigated in this study. The manufacturing sector is one of the key pillars of growth and development in the Kenyan economy as envisioned in the national strategic development blueprint "the Vision 2030". The sector is currently developing with only a handful large scale manufacturing firms which are mostly foreign owned. In contrast, this sector has very many small scale manufacturing firms owned by middle income Kenyan entrepreneurs and scattered across the major cities and towns across the country. The medium sized manufacturing firms are fewer compared to small scale manufacturing firms. The Kenyan government is currently devoting a lot of resources in supporting this sector to grow with a key focus of creating various industrial parks across the country that support the growth of local manufacturing of products.

Results from this study indicates that four out of five drivers tested have a significant positive influence on the firm's performance. These are leadership styles, human resources, technology and structure. The results indicate that strategic direction of the firm as a fifth driver only influences the other predictor variables but on its own it does not influence performance of manufacturing firms. These findings confirms the assertion by the Dynamic Capabilities View of the firm that existence of strong dynamic capabilities confers a firm the ability to achieve superior performance and competitive advantage. The study found that when dynamic capabilities are used as drivers of strategy implementation process, it enables the firm to attain better performance. The study also revealed that when dynamic capabilities work in a combined relationship, the structure of the firm and technology used takes the dominant role in influencing the firm's performance.

\section{Literature Review and Hypotheses Development}

\subsection{Firm's Performance}

Many researchers believe that the strong practices in strategic management significantly influences business firm's performance (Griffins, 2013; Hrebiniak, 2005; Jooste \& Fourie, 2010; Sage, 2015; Sial et al., 2013; Teece, 2014). Griffins (2013) define business performance as the degree to which the firm its own needs for survival and those of its stakeholders. The International Standard Organization views performance as a measurable outcome out of efficiently and effectively achievements of her goals and objectives or measurable results out of the organizations proper utilization of her actions and activities (ISO, 2015).

Performance is the sum total of all results obtained in a firm or an outcome obtained after successful efforts in implementing a strategy. In the systems approach to organizations, Bank, Carson and Nelson (1996) define a system as related parts that are harmoniously working together to achieve a common goal. A system is comprised of different components working together in a regular relationship. The common goal referred here is the overall outcome of various interactions of different components that make up a system. This is what this study refers to as firm's performance.

The Dynamic Capabilities View of the firm considers utilization of unique capabilities as the source of strong performance and competitive edge (Barney, 1991; Teece, 2014). Performance is a key construct in strategy because almost every researcher and scholar attempts to relate their constructs to firm's performance (Sorooshian et al., 2010). Combs et al., (2005) views performance as an "economic outcome arising from the interplay among organizational attributes, actions and environment. Performance is mostly measured in financial terms (Barnat, 2012) and it encompasses three specific areas namely financial performance, market performance and shareholder's return.

\subsection{Leadership Styles and Firm's Performance}

Dynamic Capability Theory views strong leadership skill as one on the key dynamic capability a firm can possess. Strong leadership help the firm to navigate, adjust well and operate efficiently in an increasingly competitive 
environment (Teece 2014). Leadership styles enables

organizations innovate and respond to the market changes by supporting people who champion new ideas, new products and product applications (Thompson \& Strickland, 2007) Organizational Leadership influences strategy implementation by providing a clear direction, up to date communications, motivating staff and setting up culture that enable organizations to excel in the market. (Griffins, 2013). There are five key leadership styles which are commonly practiced by leaders when implementing strategies (Bourgeois \& Brodwin, 1998). These styles include the commander style, collaborative, coercive, cultural and organizational change styles.

The commander and organizational change styles represents the old school approach where the leader formulates the strategy first and think about implementation latter on. Collaborative and cultural styles are more modern in that they include stakeholders as an active participant during the implementation process while the coercive leader drives the implementation process alone without consultations.

The three main leadership styles that are commonly used in many organizations are transformational, transactional and passive avoidant styles (Bass \& Avolio, 1992). Aziz, Mahmood and Abdullah (2013), tested these styles in an SME firm's setting and observed that the transformational style has the highest impact on SM E performance compared to the other two leadership styles. These findings agrees with Naeem and Tayyeb (2011) who found out that transformational leadership style has a higher positive correlation compared to transactional style with a weak positive correlation against the performance of an SM E firm. In an effort to determine whether leadership styles influence performance of the firms working in the hospitality industry in Thailand, Zumitzavani and Udchachone (2014) observed a positive influence of transformational style on performance, a weak positive influence of transactional style on performance while passive/avoidant style recorded a negative influence on organizational performance. A study by Okwachi et al., (2013) among the SM E firms in Kenya concluded that leadership styles impacts directly on the strategy implementation efforts. The findings on the foregoing leads to the following hypothesis;

H1 The Leadership style exhibited by a manager when implementing a strategy influences performance of the manufacturing firm.

\subsection{Structure and Firm's Performance}

Structures in an organization have been studied by scholars since the times of Alfred Chandler in 1960s. In an endeavor to understand how an organizational structure relates to strategy (Robbins, 2006). Chandler conducted a series of studies involving hundreds of large organizations in America and came into a conclusion that strategy changes in these companies necessitated structural adjustments. He observed that those strategies requiring organizations to expand production lines called for revision of structure in order to enable them produce more and align themselves with the demands of the new strategy. These studies led to the thinking that the structure of the firm should always follow the strategy being implemented. The study made an observation that small organizations with few lines of production tended to adopt a centralized structure which has low in terms of complexity and formality. As organizations grow and diversifies the production lines, they are required to alter and change their structures in line with the requirements of the new strategy (Robbins, 2006).

In their quest to find out how structures and managerial activities varies in different environments, Burns and Stalker (1961) studied twenty firms in Europe and made an observation that environmental dynamism affected the structures which the firms adopted. Those firms which operated in a stable environment adopted mechanistic structures which exhibited low task differentiation, low interactions between departments and task areas, formalization of procedures, tasks standardization and centralization of decision making. On the other hand, the firms that operated in a dynamic environment adopted organic structures where tasks are highly differentiated, departments are highly integrated with functional areas, faster communications with rapid sharing of information, decentralized decision making structures and less standardization, formalization of procedures and activities. This study concluded that structures adopted by firms varies and are dictated by their operating environment.

Structural dimensions that affects how the firm performs have been studied by Oslon, Slatter and Hultz (2005). In this study 200 senior managers in American companies interviewed and results indicated that performance of an organization is dictated by how closely the structure is matched with employee behavior and the strategy being pursued. The three structural dimensions that were found to influence performance are formalization, centralization and specialization. Formalized structures uses of strict rules and procedures to shape the behavior of employees and drives the activities in the entire organization. Centralization refer to the decision making authority which differ from the top to bottom level management while specialization shows how division of labour is exercised in entire 
organization.

A strong concern in this study is whether small firms have definite structures and are able to restructure when need arises. Meijaard, Brand and Mosselman (2005) found out that small firms have adopted a variety of structures which are largely dictated by the size of the firm. These structures varies in terms of how departmentation and centralization/decentralization of activities is done. Leitao and Franco (2011) observed that performance of an SME is influenced by how well an efficient structure is maintained. The foregoing literature leads to the following hypothesis;

H2 Attention to the structural needs of the firm when implementing a new strategy influences performance of the manufacturing firm.

\subsection{Human Resource and Firm's Performance}

The literature in management has substantial evidence that human resources practices influences the performance of organizations (Amin, Ismail, Rashid \& Salemani, 2014; Cho, Woods, Jang \& Erdem, 2006; Huselid, 1995; Olrando $\&$ Johnson, 2001). Studies on the relationship between human resources and performance dates back to 1995 when Huselid conducted a study on the impact of human resource practices on employee turnover, productivity and performance. In the same period Becker and Gerhart (1996) investigated the relationship between management of human resources and performance of organizations. To date the relationship between human resources and performance has been a hot topic for research.

The Resource Based View of the firm recognizes that for an organization to perform well it requires people who knowledgeable and possesses requisite skills. Quality people are a valuable assets an organization can have and when their skills are well utilized better performance can be achieved which can further lead to competitive advantage.

Barney (1991) outlined the conditions that must be fulfilled in order to convert human resources into a source of competitive advantage within the firm. That the work done by people must add value to the total production, people must possess unique skills which are difficult to find in the market, the investment a firm had put in human capital cannot be easily imitated by rival firms and that the existing technology cannot be used to substitute people. It therefore follows that the dynamic capabilities in people are usually created by the firm itself through training and development (Teece, 2014). According to Orlando and Johnson (2001), Cho et al (2006) better practices of human resources in an organization increases employees satisfaction and thus help to reduces labour turnover.

Researchers continue to argue whether the link between human resources and performance is direct or indirectly mediated by strategy. To this end, Katou (2008) studied 178 organization in Greece and observed that a relationship between human resource practices and performance in deed exists but it is partially mediated by human resource management outcomes and influenced by the strategies the organization is implementing. The results indicated that human resource policies associated with business strategies influences firms' performance through human resource management. Studies have also indicated that best human resource practices like training, recruitment performance appraisal among others significantly influences organizational performance (Beh \& Loo, 2013; Amin et al, 2014). From the foregoing we hypothesize that;

$H 3$ Attention to the human resource requirements of the firm when implementing a new strategy influences performance of the manufacturing firm.

\subsection{Technology and Firm's Performance}

Technology refers to accumulation of knowledge, innovations, products, processes, tools, procedures and organization systems developed to accomplish tasks (Damanpour, 1991).

The RBV theory views technology as an essential capability in the organization that is used by the firm make products and effectively deliver them to customers (Barney, 1991). However, in line with frequent changes that takes place in a firm, technology is viewed as a dynamic capability that is integrated in various processes and is used to enhance performance and the competitive position of a firm in a dynamic and turbulent environment (Zollo \& Winter, 2002).

Firms that are able to master and maintain strong dynamic capabilities always endeavor to develop their own unique technologies. This enable them to differentiate their products, create and maintain strong and unique processes, modify their structures and business models (Teece, 2014).

Development of strong capacity in technology means that the firm must create new experiences, inject new knowledge and skills in the existing processes (Bell \& Pavitt, 1995). According to Lall (1992) technological capability is an ongoing process in a firm involving continuous interacting with the environment to create, 
accumulate and absorb the technology required by the firm. Kumar, Kumar and Madanmohan (2004) underscores that a process learning is required by a firm in order to acquire new technological capability. The ability to create and manage changes in technologies in production is necessary if a firm has to achieve and maintain superior performance (Zawislak, Alves, Tello-Gamarra, Barbieux \& Reichert, 2012).

Since technological capability is often associated with the knowledge (Jin \& Von Zedtwitz, 2008), then it is an incremental process that is limited by the extent to which a firm can create new knowledge. In a dynamic environment, apart from knowledge, creation of technological capacity also requires innovative ideas. Innovation gives a firm an opportunity to change her production function and process and eventually build a distinctive technological competence (Teece, 2014). Several studies in the past have attempted to associate the use of superior technology to better performance and competitiveness (Nohria \& Gulati, 1996). Urich and Wayne (2005) observed that technology assist firms to maintain efficient and effective product lines hence improving her productivity. Premkumar (2003) noted that SMEs are increasingly using technology to their productivity and competitive position. According to Becheikh, Landry and Amara (2006) innovation is necessary for the firms to develop and maintain better performance in the current and future markets. Manimala and Vijay (2012) noted that new technology is essential for growth of business in the private sector. This is in agreement with Mubaraki and Aruna (2013) who observed that firms improves their performance through better application of technology. From the foregoing we hypothesize that;

H4 Attention to technological requirements when implementing a new strategy positively influences performance of the manufacturing firm.

\subsection{Strategic Direction and Performance}

Strategic direction is contained in the firm's vision and mission statements and provides the logical reason of what the firm intends to be and the resources available to get there. Strategic direction guides the firm to follow a given path at the same time advice on what to do in the long-run in line within the shareholders aspirations (Madu, 2013).

Past studies have attempted to link strategic direction and firm's performance and the results are inconsistent and mixed up (Liu \& Fu, 2011; Jantunen et al., 2005; Wiklund \& Shephend, 2005; Martin \& Lumpkin, 2003). Lumpkin and Dess, (1996) noted that strategic direction of the firm does not relate directly to performance but it is influence by many third party variables which leads to different performance levels. O'regan and Ghobadian (2006) did a study based on role of strategic direction capabilities on performance management decisions. This study found out that generic organizational capabilities positively influences deployment of strategies and the overall performance. This study concluded that generic capability is a key driver of performance and firms seeking high overall performance would well be advised to base their strategic direction on their generic capabilities. Odita and Bello (2015) conducted a study in Nigerian banks based on how strategic intentions are related to the bank's performance. The outcome revealed strategic intensions and bank's performance are positively and significantly related. The study further indicated that various dimensions of strategic direction such as goals, objectives, mission and vision are significantly related with the bank's performance. The researchers came to a conclusion that strategic direction influences bank's performance positively.

Kitonga, Bichanga and Muema (2016) studied observed that that strategic direction and performance for non-profit organization in Kenya are positively and significantly related. This implies that strategic direction is the foundation upon which strategies are crafted, developed and eventually implemented. Therefore, it is paramount that strategic direction needs to be an ambiguous to all stakeholders in the firm. Leaders in manufacturing firms should align their strategic directions with the firm's vision and mission statements. Once developed then crystallize it and cascade it downward to all employees who requires an understanding of the direction their firm is taking. Finally, it should be the impetus upon which strategic actions and activities are designed and operationalized. From the foregoing we hypothesize that;

H5 A clear focus on the firm's strategic direction when implementing a new strategy positively influences firm's performance.

\subsection{Critique of the Existing Literature and Theories}

The literature review has statistical evidence that a number of the strategy implementation drivers reviewed in this study play a key role in determining superior performance in business firms. However, The this literature leads to the thinking that only those firms paying close attention to strategic management processes are guaranteed of success (Sorooshian et al., 2010). This perspective raises fundamental questions concerning those firms which have no clue of what a 
formal strategy is and yet they succeed in their own unique ways (EC, 2003). Most studies have concentrated on strategies and organizational performance from a formal and direct perspective and largely ignored organization's informal and indirect practices (EC, 2003). According to Gakure and Armule (2013) quite a number of SMEs in Kenya do not have documented plans and yet they still perform well on their own unique ways and styles. Future studies need to look at the informal application of strategies and the performance of business organizations.

The second fundamental issue arising from the literature is why organizations fails or seriously struggles in strategy implementation despite having robust and strong strategies. Carter and Pucko (2010) point out that between $60-80 \%$ of firms globally fails or seriously struggle in their strategy implementation processes. The implications here is that the same number of firms do not have a good strategies or leadership. Many good CEOs have been fired because of strategic failures but not necessarily that they do not practice strong leadership styles (Ekelund, 2015; Forbes, 2013). Therefore, leadership styles are contingent to the environment the firm is working in and at a particular point in time. There are instances where autocratic leadership style yield better and faster results than transformational leadership. The literature has concentrated on transformational, transactional and passive/avoidant styles ignoring others (Avolio \& Bass, 2004).

A key variable under investigation in this study is organization structure. There is a mixed perception from contemporary scholars that deviates from the original thinking advanced by Chandler (1962) that "structure always follows organization's strategy". There are counter arguments in the literature that tend to point out that the opposite also holds some truth. Some scholars have argued that organization "strategy follows the structures that are already laid down in organizations" (Hall \& Saias, 1980; Bielawska, 2016). The scholars observed that while most

of the studies are in agreement with Chandler's (1962) works, the nature of the relationship between structure and strategy requires re-examination. The scholars suggested an alternative view by stating that the strategy, structure, and environment are closely intertwined. "Whereas a man builds the structure of an organization, in practice, it is this very structure that later constrains the strategic choices they make" (Hall \& Sias, 1980).

There have been divergent views on the contributions of human resources to performance in organizations and the literature has referred this as a "black box" that is often mediated by strategy (Orlando \& Johnson, 2001; Fey et al. 2007). Over the years, scholars have argued whether human resources contribute directly or indirectly to the performance in an organization (Huselid, 1995; Becker \& Gerhart, 1996; Orlando \& Johnson, 2001; Fey, Yakoushev, Katou, 2008; Beh and Loo, 2013). Some of the studies have tended to confirm the findings by Huselid (1995) that a direct link exists between human resources and organizations performance while the divergent views tends to follow Orlando and Johnson's (2001) arguments that human resource need to be mediated by other variables for it to have a positive effect on organizations performance.

Technology variable, according to the RBV (Grant, 2001) and DCV framework (Wernerfelt, 1984; Rumelt, 1984, Barney, 1991, Zollo \& Winter, 2002, Teece, 2014), and strategic direction variable (Prahalad \& Hamel, 1990, Madu, 2013) are often embedded in various organizations practices and configurations implying that they do not influence organization's performance directly. The direct treatment of these two variables in previous studies also raises a fundamental question whether these variables need to be treated directly or indirectly where they go through other variables. Past studies has taken the first approach where human resources and firm's performance have been treated directly.

While some of the past studies have documented a direct relationship between technology and organizational performance (Nohria \& Gulati, 1996; Becheikh, Landry \& Amara, 2006; Manimala \& Vijay, 2012; Mubaraki \& Aruna; 2013), similar studies in strategic directions have yielded mixed results (Lumpkin \& Dess, 1996; Odita \& Bello, 2015; Kitonga, Bichanga \& Muema; 2016). Some of these studies have found a direct relationship between strategic direction and organization performance (Odita \& Bello, 2015; Kitonga et al., 2016) while others have found that strategic direction works well when it is embedded in other strategy variables (Lumpkin \& Dess, 1996). These studies projects divergent approaches on technology and strategic direction variables. The implication here is that these variables are based on different frameworks and a unitary approach is required in future studies.

The literature review also portends a dual perspective on variation in firm's performance. The first perspective is aligned to environmental dynamism as the main cause of variations in performance (Teece et al., 1997; Teece; 2007; Teece; 2014) while the second perspective is based on resources and capabilities (Grant, 2001; Barney, 1991; Wernerfelt, 1984; Rumelt; 1984; Eisenhardt \& Martin, 2000; Teece; 2014). These mixed perspectives put scholars in a difficult situation when deciding which one to follow. This could also explain for variations in findings of the past studies as documented in strategic management literature. Several scholars in strategic management have also observed that the management literature pertaining to strategy implementation is fragmented, inconclusive and lacks 
theories or comprehensive frameworks (Noble, 1999; Okumus, 2001). However, the literature related to strategy implementation indicates that the performance is a derivative of the interactions between various components operating in the firm.

The systems theory views performance as a product of harmonious interactions of various components that must work together at all times. However, the theory does not address how the environmental factors like technological changes are likely to influence the harmonious relationships existing between sub-components and in turn affecting the performance of a firm either positively or negatively. The theory assumes that there will always be an agreement between various systems' sub-components and each system sub-components is aware of the end result which is not practically true in a highly dynamic and competitive environment. The systems theory locks out outsider components and assumes that an outstanding performance is as a result of only the sub-components working within the system only. This is also not practically true because performance in an organization may be influenced by other social-cultural, legal, economic and political factors operating outside the firm's context.

The Dynamic Capability View of the firm (DCV) attributes good performance of a firm as a result of possession of unique capabilities which are dynamic and tacit in nature and are hard to be imitated by rival firms. These unique dynamic capabilities like superior leadership skills give a firm a competitive edge over her rivals. In the DCV's approach, it is the competitive advantage that explains the superior performance in a business firm. However, the DCV framework lacks a proper grounding theory and appears to ride on the foundations of the Resource Based View (RBV) of the firm. The framework is based on limited empirical researches and evidences on dynamic capabilities making it draw conclusions from narrow qualitative empirical tests from case studies.

\subsection{The Conceptual Framework}

Strategy implementation process in this study involves the interactions between the dynamic capability drivers when implementing a new strategy in a firm. These interactions as shown in Figure 1 are deemed to have a combined influence how the firm performs in at any given time.

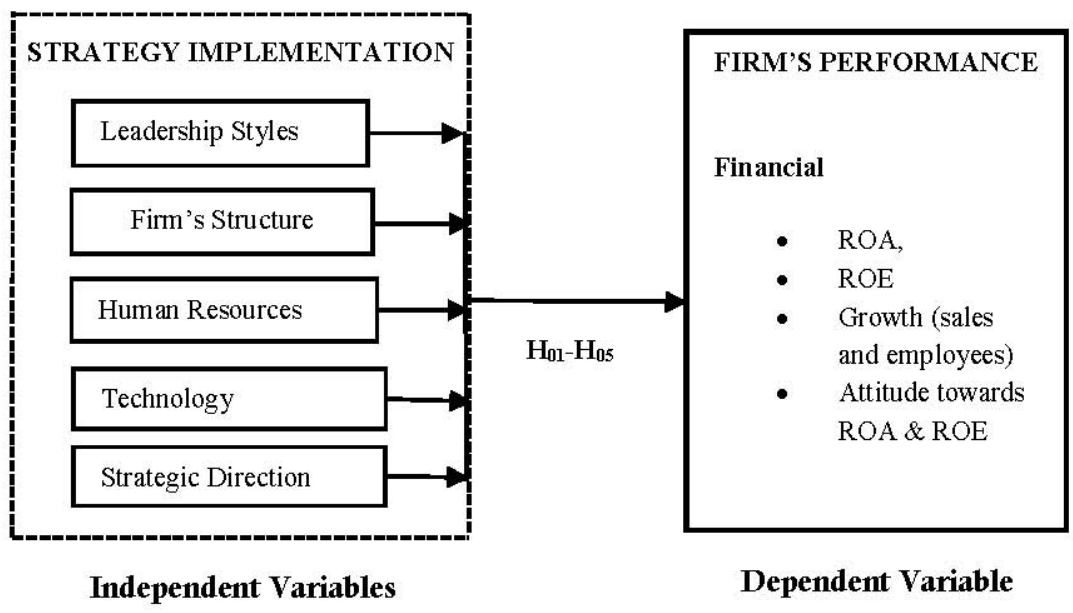

Figure 1. Influence of Dynamic Capabilities on Firm's Performance (Own Schematic)

\section{Research Methodology}

This study applied a mixed designs approach which is the triangulation of several research designs. This approach had been used by several scholars in the past in similar studies because of its ability to increase validity of the outcomes while at the same time eliminating the defects of these methods (Northhouse, 2013).

\subsection{Study Population}

The population in this study consists of 593 manufacturing firms. These firms were grouped into two main clusters according to size resulting classifications like the medium sized firms and small sized firms. However, a firm with less than 10 full time employees and annual sales of less 100,000 to 3 million USD was excluded due to the fact that 
it did not fit in well in the working definition of an SME in Kenya. Based on this criterion, 165 firms constituted the sampling frame.

\subsection{Sample Size Determination}

The study sample was selected where the sample size for a population of 10,000 or more is computed using the formula $n=p q z^{2} / e^{2}$ where, $n=$ Minimum Sample Size, $p=$ Population proportion with given characteristic, $z=$ Standard normal deviation at the required confidence level and $e=$ Error Margin. Mugenda and Mugenda (2003) recommend that since $p$ and $q$ are unknown, both are set at 50\%. At a confidence level of $95 \%$ that will be used for this study, $z=1.96$ and the sampling error of $e=+5 \%$. Thus, sample size $n$ becomes:

$N=50 * 50 *(1.96 / 5)^{2}=384$. Where a study's population is less than 10,000 the following formulae is used to calculate the sample; $n f=n /(1+n / N)$ Where, $n f$ is the desired sample size when the population is less than 10,000, $n$ $=$ sample size (when the population is greater than 10,000) $=384, N=$ estimate of the population size $=165$

$n f=n /(1+n / N)=384 /(1+384 / 165)=384 / 3.33=115$ firms. This implies that a sample size of 115 manufacturing small and medium firms were selected to participate in this study.

\subsection{Data Collection Instruments}

This study utilized questionnaires and secondary sources as the main instruments for data collection. The secondary data reviewed mainly concerned the audited financial records which gave an indication of the movement of various indicators for the period sought by the study. However, majority of these firms do not keep proper financial records. This forced this study to rely mostly on the information obtained through questionnaires.

The questionnaire included Likert scale constructs with a scale ranging from 1-5 where each respondent was required to rate each and every statement given describing a given variable. The scale ranged from $5=$ Strongly Agree, 4=Agree, $3=$ Neutral, $2=$ Disagree and $1=$ Strongly Disagree. Each and every item in the constructs was meant to measure a certain attribute of the main variable. These constructs were set in unambiguous terms allowing the respondents to react to them without wasting time. At the end open ended questions were included to allow the respondent give additional information that is not captured in the Likert scales questions.

\subsection{Data Collection Procedures}

Since the owners or CEO's are the major architect of strategy implementation in organizations, one questionnaire was administered to the owner or CEO of each firm. Due to the work commitments among the CEO's and the owners of the firms, drop and pick latter method was used for questionnaires. This gave managers enough time to reflect and respond to all questions. The researcher read, interpreted the questions and recorded the responses from those owners who could not read or write or those who indicated that they did not understand the questions well.

\subsection{Data Processing and Analysis}

Data collected from the field was cleaned and incomplete questions were excluded in the analysis. The mean score was used to analyze the Likert scale based constructs ranging from 1-5 and presented in a nominal scale and the Cronbach alpha coefficient was used to check reliability of the study instruments. Bivariate linear correlations and multiple regression analysis were used to establish the influence that independent variables has on dependent variable. In order to test the linear relationship between the various independent and the dependent variables in this study; Pearson's correlation was used where the designation $(r)$ symbolizes the correlation coefficient. This varies over a range of -1 to +1 , whereby the sign signifies the direction of the relationship. This coefficient is significant in situations where the significance level is $P<0.05$. The multiple regression output gave the coefficient of determination $\left(\mathrm{R}^{2}\right)$ and the F-statistics which were used to determine the goodness of the fit and the model validity respectively. The F-statistics is significant when p-value $P<0.05$. To test the hypotheses, the following two conditions were set such that given $\mathrm{H}_{0}$ and $\mathrm{H}_{1}$, set $\alpha=0.05$, the rule is that reject $\mathrm{H}_{0}$ if $\mathrm{P}$ - value is less than $\alpha$ else fail to reject $\mathrm{H}_{0}$ : where

$$
\begin{aligned}
& \text { 1. } \mathrm{H}_{0} \text { : Null Hypothesis: H0i: } \beta \mathrm{i}=0 \text {. Where, }(\mathrm{i}=1,2,3,4,5) \\
& \text { 2. } \mathrm{H}_{1} \text { : Alternative Hypothesis: } \mathrm{Hi}: \beta \mathrm{i} \neq 0 \text {. Where, }(\mathrm{i}=1,2,3,4,5)
\end{aligned}
$$

The bivariate correlations and multiple regression outputs was used to test the hypotheses. When $p$-value is greater 0.05 the null hypothesis $\left(\mathrm{H}_{0}\right)$ is rejected in favour of alternative hypothesis $\left(\mathrm{H}_{1}\right)$ implying that the independent variable $(\mathrm{X})$ has a significant influence on the dependent variable $(\mathrm{Y})$. On the other hand, when $p$-value is less than 0.05 , we fail to reject the null hypothesis $\left(\mathrm{H}_{0}\right)$ and conclude that there is no influence of independent variable $(\mathrm{X})$ on the dependent variable $(\mathrm{Y})$. 


\subsection{Variable Measurement}

\subsubsection{Firm's Performance}

This study relied on recorded information from the financial statements showing the level of profitability, to compute Return on Assets, Return on Equity and sales turnover. Where this information was not availed due to various reasons, a five (5) point Likert scale instrument (Boone \& Boone, 2012) was used to capture information using indirect financial measures where the degree of satisfaction with firm's performance was used based on owner's perceptions on performance. The scale ranged from $(1=$ Strongly Disagree, $2=$ Disagree $3=$ Not Sure, $4=$ Agree, $5=$ Strongly Agree). The mean score was then calculated as an average of the 5 items examined on the enterprises' perceived performance. A mean score of 3.4 and above on each item indicates that the respondents agreed with the statement given while those with a mean score below 3.4 indicates disagreement. Then the average mean score per firm was obtained from aggregating the means on performance and dividing by 5 items. The higher the score, the better the statement is in terms of the firm's perceived performance.

\subsubsection{Dynamic Capability Drivers}

Strategy implementation was used to measure the extent to which a firm pays close attention to the requirements of the key factors used to drive strategy implementation efforts in a firm. In order to measure the variables under strategy implementation (leadership styles, organizational structure, human resources and technology and strategic direction), a 5-items Likert scale was developed (Boone \& Boone, 2012) which ranged from (1= Strongly Disagree, $2=$ Disagree $3=$ Not Sure, $4=$ Agree, $5=$ Strongly Agree). The mean score was then computed as the average of the 5 items. A mean score of 3.4 and above on each item indicates that the respondents agreed with the statement given while those with a mean score below 3.4 indicates disagreement. The higher the score, the more the variable is important in influencing performance of the manufacturing firm.

\subsection{The Study Model}

This study adopted a multiple regression model to predict the extent to which each of the five independent variables $\left(\mathrm{X}_{1}, \mathrm{X}_{2}, \mathrm{X}_{3}, \mathrm{X}_{4}\right.$ and $\left.\mathrm{X}_{5}\right)$ influences the dependent variable $(\mathrm{Y})$ through strategy implementation initiatives of the manufacturing firm. The influence of $\mathrm{X}_{\mathrm{i}}, \mathrm{i}=(1,2,3,4,5)$ and $\mathrm{Y}$ is expressed in the following functional relationship;

$Y=f n\left(X_{1}, X_{2}, X_{3}, X_{4}, X_{5}\right)+\varepsilon$

Where: $Y=$ firm's performance, $X 1=$ leadership styles, $X 2=$ attention to structure, $X 3=$ attention to human resources, $\mathrm{X} 4=$ attention to technological requirements, $\mathrm{X} 5=$ the strategic direction of the firm and $\varepsilon$ is the stochastic disturbance error term. From this functional relationship, the following multiple regression model was developed;

$Y=\beta_{0}+\beta_{1} X_{1}+\beta_{2} X_{2}+\beta_{3} X_{3}+\beta_{4} X_{4}+\beta_{5} X_{5}+\varepsilon$

Where $\beta_{0}=$ Constant and $\beta_{i}=$ Coefficient of independent variable $\mathrm{X}_{\mathrm{i}}$ where $\mathrm{i}=1,2,3,4,5$.

\section{Results and Discussions}

The five dynamic capability drivers in this study were correlated against the manufacturing firm's performance and the results are presented in Table 1.

\subsection{Bivariate Linear Correlation Results}

Results in Table 1 reveals that leadership styles $\left(\mathrm{X}_{1}\right)$ has a positive and significant influence on the performance of manufacturing firm $\left(\mathrm{r}=.259^{* *}, P=.005\right)$. A leadership style has been identified by the literature as one of the key drivers in strategy implementation that influences organization performance. This means that as the leadership styles improve during the strategy implementation

process, there is a significant positive change in the firm's performance. The findings in Table 1 also indicate that structural adaptations $\left(\mathrm{X}_{2}\right)$ positively influences firm's performance $(\mathrm{r}=.442 * *, P<.001)$. Structure is one of the dynamic capabilities that influence firm performance in a dynamic environment. This means that, as the leadership in the firm adopts dynamic structures that fit and support the firms' strategy implementation efforts, the performance significantly improves. The bivariate correlations revealed that there is a positive and significant influence of human resources $\left(\mathrm{X}_{3}\right)$ on the performance of manufacturing firm during strategy implementation $\left(\mathrm{r}=.408^{* *}, P<.001\right)$. The literature identified human resources as one of the key driver that influences firm's performance positively. The findings of this study support this observation. 
Table 1. Correlation Results

\begin{tabular}{|c|c|c|c|c|c|c|c|}
\hline & & $\mathrm{Y}$ & $\mathrm{X} 1$ & $\mathrm{X} 2$ & $\mathrm{X} 3$ & $\mathrm{X} 4$ & $\mathrm{X} 5$ \\
\hline \multirow[t]{2}{*}{ Performance (Y) } & Pearson Correlation & 1 & & & & & \\
\hline & Sig. (2-tailed) & & & & & & \\
\hline \multirow[t]{2}{*}{ Leadership Styles (X1) } & Pearson Correlation & $.259 * *$ & 1 & & & & \\
\hline & Sig. (2-tailed) & .005 & & & & & \\
\hline \multirow[t]{2}{*}{ Structural Adaptations (X2) } & Pearson Correlation & $.442 * *$ & $.386^{* *}$ & 1 & & & \\
\hline & Sig. (2-tailed) & .000 & .000 & & & & \\
\hline \multirow[t]{2}{*}{ Human Resources (X3) } & Pearson Correlation & $.408 * *$ & $.337 * *$ & $.526^{* *}$ & 1 & & \\
\hline & Sig. (2-tailed) & .000 & .000 & .000 & & & \\
\hline \multirow[t]{2}{*}{ Technology (X4) } & Pearson Correlation & $.482 * *$ & $.337 * *$ & $.468 * *$ & $.525 * *$ & 1 & \\
\hline & Sig. (2-tailed) & .000 & .000 & .000 & .000 & & \\
\hline \multirow[t]{2}{*}{ Strategic Direction (X5) } & Pearson Correlation & .137 & $.527 * *$ & $.225^{*}$ & $.447 * *$ & $.358 * *$ & 1 \\
\hline & Sig. (2-tailed) & .143 & .000 & .016 & .000 & .000 & \\
\hline
\end{tabular}

$\mathrm{N}=115$

**. Correlation is significant at the 0.01 level (2-tailed).

*. Correlation is significant at the 0.05 level (2-tailed).

The study findings also indicate that technology $\left(\mathrm{X}_{4}\right)$ and performance of the manufacturing firm relates positively and significantly during strategy implementation $(\mathrm{r}=.482 * *, P<.001)$. This study intended to test whether technology is one of the key variables influencing performance of manufacturing firm during strategy implementation. The findings indicated that compared to the other four key variables (leadership styles, structural adaptations, human resource and strategic direction), technology has the strongest influence on the manufacturing firm's performance. Lastly, the study found no significant influence of the firm's strategic direction $\left(\mathrm{X}_{5}\right)$ on manufacturing firm's performance $(\mathrm{r}=.137, P=.143)$. Results in Table 1 also reveals that there is high and significant correlations among all the dynamic capability variables. This implies that they interacts and positively influence one another.

\subsection{Multiple Linear Regression Results}

Table 2. ANOVA: Model Validity

\begin{tabular}{llllll}
\hline Model & Sum of Squares & df & Mean Square & F & Sig. \\
\hline Regression & 7.830 & 5 & 1.566 & 9.314 & $.000 \mathrm{~b}$ \\
Residual & 18.160 & 108 & .168 & & \\
Total & 25.990 & 113 & & & \\
\hline
\end{tabular}

a. Dependent Variable: Performance

b. Predictors: (Constant), X5, X4, X3, X2, X1

Results presented in Table 2 show that the study model $Y=\beta_{0}+\beta_{1} X_{1}+\beta_{2} X_{2}+\beta_{3} X_{3}+\beta_{4} X_{4}+\beta_{5} X_{5}+\varepsilon$ is valid $\left(\mathrm{F}_{(5,108)}=9.314, P<.001\right)$ meaning the all the five dynamic capability drivers in this study are good predictors of variations in performance of the manufacturing firm. 
Table 3. Model Summary

\begin{tabular}{|c|c|c|c|c|c|}
\hline Model & $\mathrm{R}$ & R Square & $\begin{array}{l}\text { Adjusted R } \\
\text { Square }\end{array}$ & $\begin{array}{l}\text { Std. Error of the } \\
\text { Estimate }\end{array}$ & Durbin-Watson \\
\hline & $.549^{\mathrm{a}}$ & .301 & .269 & .41006 & 2.429 \\
\hline
\end{tabular}

Results in Table 3 indicate that all the five dynamic capability drivers in this study explains thirty percent (30.1\%) of the total variations in the performance of the manufacturing firm. The Durbin-Watson statistics $(d=2.429)$ indicate absence of autocorrelation. According to the Durbin and Watson (1950) statistics, the values of $d$ always lie between 2.00 and 4.00. The value of $d U, \alpha,=2.00$ indicate the absence of autocorrelation. When the value of $d$ below 2.00, $(d<d U, \alpha)$ autocorrelation is present and when $d$ is above $2.00,(d>d U, \alpha)$ indicate autocorrelation is absent.

Table 4. The Multiple Regression Variable Weights

\begin{tabular}{llllllll}
\hline \multirow{2}{*}{ Model } & \multicolumn{2}{l}{$\begin{array}{l}\text { Unstandardized } \\
\text { Coefficients }\end{array}$} & $\begin{array}{l}\text { Standardized } \\
\text { Coefficients }\end{array}$ & $\mathrm{t}$ & \multicolumn{3}{l}{$\begin{array}{l}\text { Collinearity } \\
\text { Statistics }\end{array}$} \\
\cline { 2 - 8 } & $\mathrm{B}$ & Std. Error & Beta & & & Tolerance & VIF \\
\hline Constant & 3.756 & .039 & & 97.433 & .000 & & \\
Leadership & .106 & .109 & .097 & .974 & .332 & .654 & 1.530 \\
Structure & .308 & .155 & .200 & 1.994 & .049 & .645 & 1.551 \\
HR & .212 & .133 & .171 & 1.587 & .115 & .558 & 1.792 \\
Technology & .279 & .086 & .320 & 3.239 & .002 & .663 & 1.508 \\
Strategic Direction & -.175 & .121 & -.152 & -1.442 & .152 & .581 & 1.720 \\
\hline
\end{tabular}

a. Dependent Variable: Performance

Results in Table 4 indicate that only attention to technological requirements (X4) during strategy implementation ( $\beta 4$ $=0.320, P=.002)$ and the structural adaptations $(\mathrm{X} 2)$ of the firm $(\beta 2=.200, P=.049)$ are significant and positively influences the firm's performance. The constant $(\beta 0)$ is also positive and significant $(\beta 0=3.756, P<.001)$. All the other three variables, that is, leadership styles (X1), attention to human resources (X3) and awareness of the strategic direction $(\mathrm{X} 5)$ have a p-value greater than $5 \%(P>0.05)$ meaning that, in a combined relationship, these variables are insignificant in explaining variations in performance of the manufacturing firm. These results in are not affected by multi-collinearity since VIF factor in all variables is less than ten (10).

\subsection{Discussions of the Overall Model}

The multiple regression results in Table 4 established that only constant $(\beta 0=3.756, P<.001)$, technology $(\beta 4=$ $0.320, P=.002)$ and structural adaptations $(\beta 2=0.308, P=.049)$ significantly influence the manufacturing firm's performance when all the dynamic capability drivers are combined. This means that the technology and structure are the two most important drivers influencing performance of a manufacturing firm. These findings are consistent with observations on techno-structure by Mintzberg (1980). For a strategy to be well implemented, the organization has to maintain a fair balance between technology and structure in a machine bureaucracy as advanced by Mintzberg (1980). Based on the findings the study rejected the null hypotheses H02 and H04 in favour of H2 and H4 and conclude that the structural adaptations and technology significantly influences the performance of the manufacturing firm. On the other hand, this study fails to reject H01, H03 and $\mathrm{H} 05$ and conclude that, in a combined relationships, there are no significant influence among leadership styles practiced, human resource practices and awareness of strategic direction on the manufacturing firm's performance. 
Table 5. Summary of Hypotheses Tested

\begin{tabular}{llllllll}
\hline No. & Variable & $\begin{array}{l}\boldsymbol{P} \text {-Value } \\
\text { Correlation }\end{array}$ & Direction & Deduction & $\begin{array}{l}\text { P-Value } \\
\text { Regression }\end{array}$ & Direction & Deduction \\
\hline H1 & Leadership styles & 0.005 & Positive & Reject H01 & 0.332 & Positive & Fail to reject H01 \\
H2 & Structure & $<.001$ & Positive & Reject H02 & 0.049 & Positive & Reject H02 \\
H3 & Human Resource & $<.001$ & Positive & Reject H03 & 0.115 & Positive & Fail to reject H03 \\
H4 & Technology & $<.001$ & Positive & Reject H04 & 0.002 & Positive & Reject H04 \\
H5 & Strategic Direction & 0.143 & Positive & Fail to reject H05 & 0.152 & Negative & Fail to reject H05 \\
\hline
\end{tabular}

Table 5 presents a summary of hypotheses tested using bivariate correlations and multiple regression analysis. The results show that only structure, technology and strategic direction posted consistent results in both tests. Hypotheses tested show that leadership styles and human resource results are inconsistent in both correlation and multiple regression tests.

\section{Conclusion}

This study posted mixed results on the influence of leadership styles and attention to human resources during strategy implementation process. While the results from bivariate linear correlations in Table 1 indicate that both variables influence the firm's performance, the multiple regression results in Table 4 indicates otherwise. Only technology, structure and strategic direction posted consistent results in both tests. It can be concluded that dynamic capabilities can be utilized in driving strategy implementation efforts in a manufacturing firm. It is also important to note that when all dynamic capability drivers are working together the role of leadership styles, human resources and strategic direction is taken by the structure and technology in a techno-structure relationship advanced by Minzberg (1980). This study confirms the Dynamic Capability View (DVC) argument on the importance of dynamic capabilities in driving firm's performance. However, the study also go a step further in identifying key capabilities that influences firm's performance during strategy implementation.

\section{References}

Amin, M., Ismail, W., Rasid, S., \& Salemani, R. (2014). The impact of human resource management practices on performance: Evidence from a Public University. The TQM Journal, 26(2), 125 - 142. https://doi.org/10.1108/TQM-10-2011-0062

Avolio, B., \& Bass, B. (2004). Multifactor Leadership Questionnaire. Mind Garden, Inc., 17, 22-36.

Awino, Z. (2013). Strategic planning and competitive advantage of ICT small and medium enterprises in Kenya. Business and Management Horizons J., 1, 1. https://doi.org/10.5296/bmh.v1i1.3942

Aziz, R., Mahmood, R., \& Abdullah, M. (2013). The effects of leadership styles and entrepreneurial orientation on the business performance of SMEs in Malaysia. The IBEA International Conference on Business, Economics and Accounting-Bangkok, Thailand.

Banks, J., Carson, J., \& Nelson, B. (1996). Discrete-event system simulation. (2nd Ed.). Upper Saddle River, NJ: Prentice-Hall.

Barnat, R. (2012). Introduction to Management. Available online: NOW: Design, n.d. Web. Retrieved 12 Sep 2016 from http://www.introduction-to-management.24xls.com/en222

Barney, J. (1991). Firm Resources and Sustained Competitive Advantage. Journal of Management, 17, 99-120. https://doi.org/10.1177/014920639101700108

Bass, B., \& Aviolo, B. (1992). Multifactor Leadership Questionnaire - Short Form 6S. Binghamton, NY: Center for Leadership Studies. In B. M. Bass's Measures for Leadership Development Multifactor Leadership Questionnaire (MLQ). Retrieved May 6, 2015 from http://www.uwec.edu/Ssow/Meares/Leadership-MLQ.htm

Becker, B., \& Gerhart, B. (1996). The impact of human resource management on organizational performance: Progress and prospects. Academy of Management Journal, 39(4), 779 -801. 
Beh, L., \& Loo, L. (2013). Human resource management best practices and firm performance: A universalistic perspective Approach. Serbian Journal of Management, 8(2), 155-167. https://doi.org/10.5937/sjm8-4573

Bell, M., \& Pavitt, K. (1995). The development of technological capabilities. Trade, Technology and International Competitiveness. Economic Development Institute of the World Bank, 69-100.

Becheikh, N., Landry, R., \& Amara, N. (2006). Lessons from Innovation Empirical Studies in the Manufacturing Sector: A Systematic Review of the Literature from 1993-2003. Technovation, 26(5/6), 644-64. https://doi.org/10.1016/j.technovation.2005.06.016

Bielawska, A. (2016). Perceived mutual impact of strategy and organizational structure: Findings from the high technology enterprises. Journal of Management \& Organization; 22(5). http://dx.doi.org/10.1017/mo.2015.55

Boone, H., \& Boone, A. (2012). Analysing Likert data. Journal of Extension, 50(2). Retrieved from http://www.joe.org/joe/2012april/pdf/JOE_v50_2tt2.pdf

Bourgeois, L., \& Brodwin, D. (1998). Linking planning and implementation. Wit, B. de/Meyer, R. 682-691.

Burns, T., \& Stalker, G. (1961). The management of innovation. London: Tavistock Publications.

Carter, T., \& Pucko, D. (2010). Factors of effective strategy implementation: Empirical evidence from Slovenian business practice. Journal for East European Management Studies, 15(3), 207-236. https://doi.org/10.5771/0949-6181-2010-3-207

Chandler, A. (1962). Strategy and structure. Cambridge, MA: MIT Press.

Cho, S., Woods, R., Jang, S., \& Erdem, M. (2006). Measuring the impact of human resource management practices on hospitality firm's performances. Hospitality Management Journal, 25(2), 262-277. https://doi.org/10.1016/j.ijhm.2005.04.001

Combs, J., Crook, T., \& Shook, C. (2005). The dimensionality of organizational performance and its implications for strategic management research. In D. J. Ketchen (Ed.), Research methodology in strategy and management, 2, 259-286. https://doi.org/10.1016/S1479-8387(05)02011-4

Damanpour, F. (1991). Organizational Innovation: a meta-analysis of effects of determinants and moderators. Academy of Management Journal, 34, 555-590.

Durbin, J., \& Watson, G. (1950). Testing for Serial Correlation in Least Squares Regression. I. Biometrika, 37(3-4), 409-428. https://doi.org/10.1093/biomet/37.3-4.409

EC. (2003). Does Implementation Matter? Informal Administration Practices and Shifting Immigrant Strategies in Four Member States, European Commission Publications: HPSE-CT-1999-00001. Retrieved from https://cordis.europa.eu/pub/citizens/docs/hpse-ct-1999-00001iapasis21703.pdf

Ekelund, H. (2015). Why some CEOs Fail and Others Succeed. Bts. Retrieved from http://www.bts.com/docs/default-source/newsletter/BTS_Insights_Why_CEOs_Fail

Eisenhardt, K., \& Martin, J. (2000). Dynamic capabilities: what are they? Strategic Management Journal, 21, 1105-1121. https://doi.org/10.1002/1097-0266(200010/11)21:10/11\%3C1105::AID-SMJ133\%3E3.0.CO;2-E

Fey, C., Yakoushev, M., Park, H., \& Bjorkman, I. (2007). Opening the black box of the relationship between HRM practices and firm performance. A comparison of USA, Finland and Russia. Stockholm School of Economics Russia- Working Paper No. 7 -101.

Forbes (2013). The Worst CEO Screw-Ups of 2013. Retrieved from http://www.forbes.com/sites/susanadams/2013/12/18/

Gakure, R., \& Amurle, G. (2013). Strategic planning practices in ICT SMEs in Kenya: What other SMEs can learn. Prime Journal of Social Sciences, 2(6), 336-349.

Grant R. (1991). The Resource-Based Theory of Competitive Advantage: Implications for Strategy Implementation. California Management Review, 33(3), 114-135. https://doi.org/10.2307/41166664

Griffin, R. (2013). Fundamentals of Management (7th ed.). Cengage South Western Publishers (USA).

Hall, D., \& Sias, M. (1980). Strategy follow structure! Strategic Management Journal, 1, 149-163. https://doi.org/10.1002/smj.4250010205

Hamel, G., \& Prahalad, C. (1989). Strategic intent. Harvard Business Review, 67(3), 63- 76. 
Hrebiniak, L. (2005). Making Strategy Work: Leading Effective Execution and Change. New Jersey: Wharton School Publishing.

Hrebiniak, L., \& Joyce, W. (1984). Implementing Strategy. New York: Macmillan Publishing Company.

Huselid, M. (1985). The impact of human resources management practices on turnover, productivity and corporate financial performance. Academy of Management Journal, 38(3), 635-672.

ISO (2015). How automating your quality management solution will help foster compliance. Geneva, Switzerland.

Jantunen, A., Nummela, N., Puumalainen, K., \& Saarenketo, S. (2008). Strategic orientations of born globals - Do they really matter? Journal of World Business, 43(2), 158-170. https://doi.org/10.1016/j.jwb.2007.11.015

Jin, J., \& Von Zedtwitz, M. (2008). Technological capability development in China mobile phone industry. Technovation, 28, 327-334. https://doi.org/10.1016/j.technovation.2007.06.003

Jooste, C., \& Fourie, B. (2009). The role of strategic leadership in effective strategy implementation: Perceptions of South African strategic leaders. South African Business Review, 13(3).

Katou, A. (2008). Measuring the impact of HRM on organizational performance. Journal of Industrial Engineering \& Management, l(2), 199-142. https://doi.org/10.3926/jiem.2008.v1n2.p119-142

Kitonga, D., Bichanga, W., \& Muema, B. (2016). The role of determining strategic direction on not-for-profit organizational performance in Nairobi County in Kenya. International Journal of Scientific \& Technology Research, 5(5), 28-32.

Kumar, U., Kumar, V., \& Madanmohan, T. (2004). Import-led technological capability: a comparative analysis of Indian and Indonesian manufacturing firms. Technovation, 24, 979-993. https://doi.org/10.1016/S0166-4972(03)00030-0

Lall, S. (1992). Technological capabilities and industrialization. World Development, 20(2), 165-186. https://doi.org/10.1016/0305-750X(92)90097-F

Leitao, J., \& Franco, M. (2011). Individual entrepreneurship capacity and small and medium enterprise (SME) performance: A human and organizational capacity approach. African Journal of Business Management, 5(15), 6350-6365. https://doi.org/10.2139/ssrn.1118257

Li, Y., Gouhui, S., \& Eppler, M. (2008). Making strategy work: A literature review of factors influencing strategy implementation. ICA Working Paper 2/2008, Institute of Corporate Communication, Univesita della Svizzera Italiana.

Liu, B., \& Fu, Z. (2011). Relationship between strategic orientation and organizational performance in Born Global: A Critical Review. International Journal of Business and Management, 6(3), 109-115. https://doi.org/10.5539/ijbm.v6n3p109

Lumpkin, G., \& Dess, G. (1996). Clarifying the entrepreneurial orientation construct and linking it to performance. Academy of Management Review, 21(1), 135-172. https://doi.org/10.5465/amr.1996.9602161568

Madu, B. (2013). Vision: the relationship between a firm's strategy and business model. Journal of behavioral studies in business, 1(9).

Manimala, M., \& Vijay, D. (2012). Technology Business Incubators (TBIs): A Perspective for the Emerging Economies. IIM Bangalore Research Paper No. 358. http://dx.doi.org/10.2139/ssrn.2117720

Martin, L., \& Lumpkin, T. (2003). From EO to "Family Orientation": Generational Differences in the Management of Family Businesses. Paper presented at the 22nd Babson College Entrepreneurship Research Conference, Babson College.

Meijaard, J., Brand, M., \& Mosselman, M. (2005). Organizational structure and performance in Dutch small firms. Small Business Economics, 25(1), 83-96. http://dx.doi.org/10.1007/s 11187-005-4259-7

Mintzberg, H. (1980). Structure in 5's: A synthesis of the research on organization design. Management Science, 26(3), 322-341. https://doi.org/10.1287/mnsc.26.3.322

Mubaraki, H., \& Aruna, M. (2013). Technology Innovation for SME Growth: A Perception for the Emerging Economies. Journal of Economics and Sustainable Development, 4(3), 156-162.

Mugenda, O., \& Mugenda, A. (2003). Research Methods - Quantitative and Qualitative Approaches. Nairobi: ACT Press. 
Naeem, H., \& Tayyeb, M. (2011). The Influence of the SMES Top-Level Managers' Leadership Styles and Their Entrepreneurial Orientation on the Business Performance. Retrieved from http://dx.doi.org/10.2139/ssrn.1884069

Noble, C. (1999). The Eclectic Roots of Strategy Implementation Research. Journal of Business Research, 45, 119-134. https://doi.org/10.1016/S0148-2963(97)00231-2

Nohria, N., \& Gulati, R. (1996). Is slack good or bad for innovation? Academy of Management Journal, 39(5), 1245-1264. https://doi.org/10.5465/256998

Northhouse, P. (2013). Leadership theory and practice (6th ed.), Thousand Oaks, CA: Sage Publications, Inc.

Odita, A., \& Bello, A. (2015). Strategic intent and organizational performance: A study of Banks in Asaba Delta State in Nigeria. Information and Knowledge Management, 5(4), 60-71.

Okumus, F. (2001). Towards a strategy implementation framework. International Journal of Contemporary Hospitality Management, 13(7), 327-338. https://doi.org/10.1108/09596110110403712

Okwachi, S., Gakure, R., \& Ragui, M. (2013). Business Models-What is their effect on the implementation of strategic plans by SME's. Prime Journal of Business Administration and Management, 3(5), 1025-1032.

O'regan, N., \& Ghobadian, A. (2006). The importance of capabilities for strategic direction and performance. Management Decisions, 42(2), 292-313. https://doi.org/10.1108/00251740410518525

Orlando, C., \& Johnson, N. (2001). Strategic Human Resource Management effectiveness and firm performance. Int. Journal of Human Resource Management, 12(2), 299-310. https://doi.org/10.1080/09585190010015105

Oslon, E., Slater, S., \& Hult, T. (2005). The importance of structure and process to strategy implementation. Business Horizon Journal, 48, 47-54. https://doi.org/10.1016/j.bushor.2004.10.002

Premkumar, G. (2003). A meta-analysis of research on information technology implementation in small businesses. Journal of Organizational Computing and Electronic Commerce, 13(2), 91-121. https://doi.org/10.1207/S15327744JOCE1302_2

Prahalad, C, \& Hamel, G. (1990). The core competence of the corporation. Harvard Business Review, 68(3), 79-91.

Robbins, S. (2006). Organization theory (Mahdi Alvani and Danaeefard), Trans (14th Ed.). Tehran: SAFFAR publication.

Rumelt, R. (1984). Towards a strategic theory of the firm. In R. Lamb (ed.), Competitive Strategic Management. Prentice-Hall, Englewood Cliffs, NJ, pp. 556-570.

Sage, S. (2015). 5 questions to evaluate your implementation strategy. Retrieved from http://onstrategyhq.com/resources/strategic-implementation/

Sial, A., Usman, M., Zufiqar, S., Satti, A., \& Khursheed, I. (2013). Why do public sector organizations fail in implementation of strategic plan in Pakistan. Public Policy and Administration Journal, 3(1).

Sorooshian, S., Norzima, Z., Yusuf, I., \& Rosnah, Y. (2010). Effects analysis on strategy implementation drivers. World Applied Sciences Journal, 11(10), 1255-1261.

Teece, D. (2014). A dynamic capabilities-based entrepreneurial theory of multinational enterprise. Journal of International Business Studies, 45, 8-37. https://doi.org/10.1057/jibs.2013.54

Teece, D. (2007). Explicating dynamic capabilities: The nature and micro foundations of (sustainable) enterprise performance. Strategic Management Journal, 28(13), 1319-1350. https://doi.org/10.1002/smj.640

Teece, D., Pisano, G., \& Shuen, A. (1997). Dynamic capabilities and strategic management. Strategic Management Journal, 18(7), 537-533. https://doi.org/10.1002/(SICI)1097-0266(199708)18:7\%3C509::AID-SMJ882\%3E3.0.CO;2-Z

Thompson, A., Strickland, A., \& Gamble, J. (2007). Crafting and Executing Strategy - Texts and Readings. (15th Ed.). New York: McGraw-Hill Irwin.

Urich, D., \& Wayne, B. (2005). HRM value of proposition. Boston, Harvard Business Press.

Wernerfelt, B. (1984). A Resource-Based View of the firm. Strategic Management Journal, 5, 171-180. https://doi.org/10.1002/smj.4250050207

Wiklund, J., \& Shepherd, D. (2005). Entrepreneurial orientation and small business performance: a configurationally 
approach. Journal of Business Venturing, 20(1), 71-91. https://doi.org/10.1016/j.jbusvent.2004.01.001

Zawislak, P., Alves, A., Gamarra, J., Barbieux, D., \& Reichert, F. (2012). Innovation capability: From technology development to transaction capability. Journal of Technology Management and Innovation, 7(2), 14-27. https://doi.org/10.4067/S0718-27242012000200002

Zollo, M., \& Winter, S. (2002). Deliberate learning and the evolution of dynamic capabilities. Organization Science, 13, 339-351. https://doi.org/10.1287/orsc.13.3.339.2780

Zumitzavani, V., \& Udchachone, S. (2014). The Influence of Leadership Styles on Organisational Performance Mediated by Organisational Innovation: A Case Study of the Hospitality Industry in Thailand. International Conference on Economics, Management and Development. 